\title{
PERILAKU KREATIF PEKERJA CALL CENTER: PERAN KOMUNIKASI DAN DUKUNGAN TRAINING CENTER
}

\author{
Nugroho J. Setiadi \\ Management Department, School of Business Management, BINUS University \\ Jln. K. H. Syahdan No. 9, Palmerah, Jakarta Barat 11480 \\ nsetiadi@binus.edu
}

\begin{abstract}
Call center business in Indonesia is growing rapidly worldwide. This condition has had repercussions for a growing number of call center workers needed. They are forced to be more creative in performing their duties. This study aims to determine the role of communication and training center in supporting the creative performance of workers in call centers. The survey was conducted by distributing questionnaires to 100 respondents (employees) of the 3 major companies in the field of telecommunication services in Indonesia. Regression analysis was used to analyze the data to examine the role of communication and training support center on creative performance. The results indicated that communication and training support center significantly influence the creative behavior in call center workers. Communication quality shown in the telecommunication service provider companies, such as the media quality, simplicity of information, dissemination of information, loads of information, and accuracy of messages, has shown good quality. In addition, the training program has shown its support for call center workers in the form of program effectiveness through research and data collection, determining the materials, training methods, choosing a coach, preparing facilities, selecting and implementing the program.
\end{abstract}

Keywords: communication, call center industry, creative behavior, training center

\begin{abstract}
ABSTRAK
Bisnis call center bertumbuh pesat secara internasional. Perkembangan industri call center yang cepat makin menambah jumlah pekerja call center yang dituntut lebih kreatif dalam melaksanakan tugasnya. Penelitian ini bertujuan untuk mengetahui peran komunikasi dan dukungan training center dalam menunjang kinerja kreatif para pekerja di call center. Survei langsung dilakukan melalui penyebaran kuesioner kepada 100 responden (karyawan) dari 3 perusahaan besar dalam bidang jasa telekomunikasi di Indonesia. Regression analysis digunakan dalam analisis data untuk menguji peran komunikasi dan dukungan training center terhadap kinerja kreatif. Hasilnya menunjukkan bahwa komunikasi dan dukungan training center berpengaruh secara signifikan terhadap perilaku kreatif para pekerja di call center. Kualitas komunikasi yang diperlihatkan di ketiga perusahaan provider layanan jasa telekomunikasi, yaitu kualitas media, kemudahan informasi, penyebaran informasi, beban informasi, dan ketepatan pesan telah menunjukkan kualitas yang baik. Di samping itu, program pelatihan telah memperlihatkan dukungannya untuk para pekerja call center melalui efektivitas program dalam bentuk penelitian dan pengumpulan data, penentuan materi, penentuan metode pelatihan, pemilihan pelatih yang dibutuhkan, persiapan fasilitas, pemilihan peserta, dan pelaksanaan program sebaikbaiknya.
\end{abstract}

Kata kunci: komunikasi, industri call center, perilaku kreatif, training center 


\section{PENDAHULUAN}

Bagi banyak organisasi bisnis, karyawan yang berbakat merupakan modal utama untuk keunggulan bersaing. Apalagi bagi pelaku bisnis di industri call center yang mulai tumbuh pesat di Indonesia, pekerja di bagian ini sangat dituntut untuk memiliki kinerja kreatif. Jika organisasi bisnis tersebut melakukan persaingan yang berdasarkan pada ide-ide baru, layanan pelanggan yang sangat baik atau cepat, keputusan-keputusan yang akurat, sangatlah penting untuk memiliki karyawan yang sangat baik. Menurut Mathis dan Jackson (2004): "Human are a necessary, varied, and sometimes problematic resource that most organization must use to a greater or lesser degree." Manusia merupakan sumber yang penting, bervariasi dan terkadang menjadi masalah bagi organisasi.

Salah satu faktor dominan dalam dunia pekerjaan yang selalu berubah hingga saat ini adalah perkembangan computer dan teknologi informasi, termasuk industri call center. Call center, menurut HSE/local authority circular (LAC), adalah lingkungan kerja yang bisnis utamanya dilakukan melalui telepon dan menggunakan peralatan display screen secara bersamaan (Sprigg, Smith, \& Jackson, 2003). Bisnis call center tumbuh pesat secara internasional. Sekitar 5\% dari seluruh pekerja di Amerika Serikat dan 2\% di Eropa bekerja di unit call center. Call center dikatakan merupakan penyedia lapangan pekerjaan yang makin tumbuh di Eropa saat ini. Sekitar 37\% dari semua pekerjaan baru di Eropa selama beberapa tahun terakhir adalah pekerja call center. Diperkirakan pertumbuhan tahunan call center di Asia Tenggara dan India adalah 50\% (Sprigg, Smith, \& Jackson, 2003).

Banyak penelitian telah dilakukan tentang call center di lingkungan kerja. Beberapa hasil penelitian menyebutkan bahwa bentuk pekerjaan call center adalah aktivitas berulang, Taylorisme, dan stres yang tinggi. Selain itu, studi tentang call center di Bandung (Jerry \& Sunaryo, 2009), menunjukkan jadwal yang ketat (waktu siaga sekitar 7 jam dengan tambahan aux-time/sisa 1,5 jam). Pergeseran jadwal kerja juga menyebabkan insomnia. Jadwal yang ketat dan kebijakan tentang pergeseran jadwal kerja setiap 5 hari membuat pekerjaan tidak mudah. Hal ini sangat sulit untuk bekerja dengan mengubah pergeseran dan tetap menyeimbangkan kehidupan sosial. Selain itu, pekerjaan call center adalah pekerjaan multitask dengan beban kognitif tinggi. Agen call center harus menghadapi berbagai pengguna (konsumen) dengan multikarakter, berbagai masalah dengan multisolusi, dan dalam melakukan pekerjaan mereka harus selalu ramah namun dituntut dengan produktivitas yang tinggi. Pekerjaan multitask ini membutuhkan berbagai keterampilan, misalnya keterampilan untuk membuka aplikasi, mencari solusi kepada pengguna jasa, dengan kegiatan dokumen, semuanya dilakukan secara paralel ketika menghadapi tiap individu/konsumen. Oleh karena itu, jenis pekerjaan seperti ini menuntut pekerja untuk selalu mencari cara baru dan gagasan-gagasan segar agar mereka tidak cepat bosan dalam melaksanakan tugas. Tuntutan berperilaku kreatif ini memang tak mudah, dan untuk itu perlu peran komunikasi yang terbangun secara kondusif di tempat kerja. Di samping itu, dukungan organisasi dalam hal fasilitas training center untuk membekali para pekerja dengan sumber-sumber motivasi baru dapat membantu para pekerja menemukan cara baru dalam menangani persoalan yang dihadapi pada saat bekerja.

\section{Tinjauan Pustaka}

Psikolog dan ahli biologi telah mengusulkan sejumlah definisi perilaku kreatif dalam sistem alam. Pada diri manusia perilaku kreatif dapat didefinisikan sebagai perilaku yang menghasilkan produk yang unik atau berharga baik untuk individu maupun masyarakat. Atau, dari sudut pandang behaviouristic, perilaku kreatif mungkin didefinisikan sebagai respons unik atau pola jawaban tertentu atas stimulus yang dapat membedakan secara diskriminatif internal ataupun eksternal (Foster, 2012).

Komunikasi, atau dalam bahasa Inggris communication, berasal dari bahasa latin communicatio, dan bersumber dari kata communis yang berarti sama. Sama di sini maksudnya adalah 
sama makna. Komunikasi minimal harus memiliki kesamaan makna antara dua pihak yang terlibat. Komunikasi dikatakan minimal karena kegiatan komunikasi tidak hanya informatif, yakni agar orang lain mengerti dan tahu, tetapi juga persuasif, yakni agar orang lain bersedia menerima suatu paham atau keyakinan untuk melakukan suatu perbuaan atau kegiatan.

Ada beberapa definisi yang dikemukakan para ahli untuk memberikan batasan terhadap yang dimaksud dengan komunikasi. Himstreet dan Baty dalam Purwanto (2006) mengemukakan bahwa komunikasi adalah suatu proses pertukaran informasi antarindividu melalui suatu sistem yang biasa (lazim) baik dengan simbol-simbol, sinyal-sinyal maupun perilaku atau tindakan. Menurut Hovland dalam Effendy (2003) komunikasi adalah upaya yang sistematis untuk merumuskan secara tegas asasasas penyampaian informasi serta pembetulan pendapat dan sikap. Sedangkan menurut Mulyana (2001) komunikasi adalah penyampaian pesan yang dapat melalui media tegas asas-asas penyampaian informasi serta pembetulan pendapat dan sikap-sikap. Demikian juga Davis dalam Mangkunegara (2004) menyatakan: "Communication is the transfer of information and understanding from one person to another person."

Tujuan dari penelitian ini adalah untuk mengidentifikasi faktor-faktor yang dapat meningkatkan kinerja kreatif karyawan call center. Pelatihan merupakan salah satu solusi peningkatan kinerja kreatif karyawan. Dessler (2006) menyebutkan: "Training refers to the methods used to give new or present employees the skill they need to perform their jobs." Pelatihan mengacu pada metode yang digunakan untuk memberikan keterampilan yang dibutuhkan karyawan untuk meningkatkan kinerja mereka dalam pekerjaan. Oleh karena itu, pelatihan yang diperuntukkan bagi karyawan call center mengacu pada metode untuk meningkatkan pengetahuan karyawan dalam pekerjaan mereka. Hal ini sama seperti yang disampaikan oleh Noe, et al (2006), yaitu: The goal of training is for employees to master the knowledge, skill, and behavior emphasized in training programs and to their day-to-day activities. Menurut Noe (2012) ada beberapa hal yang perlu ditingkatkan dalam pelatihan, yaitu: (1) pengetahuan karyawan terhadap pekerjaan; (2) keterampilan, dan (3) perilaku karyawan dalam menjalankan tugas sehari-hari.

\section{Model Kerangka Penelitian dan Hipotesis} Gambar 1.

Penelitian ini menggunakan pendekatan kerangka penelitian seperti yang disajikan pada

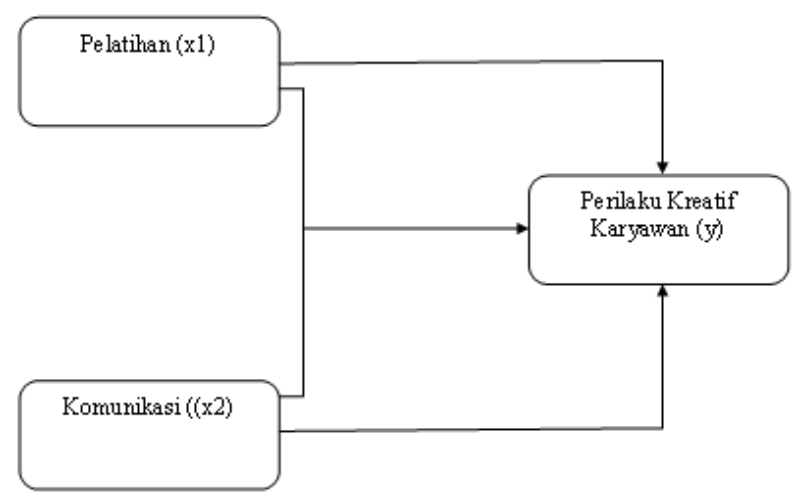

Gambar 1 Kerangka Pemikiran

Hipotesis yang akan diuji dalam penelitian ini adalah ada atau tidaknya pengaruh yang ditimbulkan oleh variabel independen (variabel X) terhadap variabel dependen (variabel Y) baik secara langsung maupun tidak langsung, serta untuk mengetahui kuat atau tidaknya hubungan antara kedua variabel tersebut. Oleh karena itu, hipotesis yang dikembangkan dalam penelitian ini adalah: 


\begin{abstract}
Hipotesis 1
Terdapat pengaruh yang positif antara pelatihan dan perilaku kreatif Karyawan Call Center.
\end{abstract}

\author{
Hipotesis 2 \\ Terdapat pengaruh yang positif antara komunikasi dan perilaku kreatif Karyawan \\ Call Center.
}

\title{
Hipotesis 3
}

Terdapat pengaruh yang positif dan signifikan antara Pelatihan dan Komunikasi terhadap Kinerja kreatif Karyawan Call Center.

\section{METODE PENELITIAN}

Objek penelitian ini adalah perusahaan yang bergerak pada sektor jasa telekomunikasi. Sedangkan populasi penelitian ini adalah karyawan perusahaan/instansi jasa tersebut yang bekerja di unit call center. Pengambilan sampel dilakukan seobjektif mungkin sehingga diharapkan dapat memenuhi syarat-syarat pengambilan sampel secara probabilistis. Sampel yang terambil diharapkan dapat merepresentasikan populasinya. Karyawan yang bersedia berpartisipasi pada penelitian ini berjumlah 100 orang. Sebagian besar responden adalah wanita yaitu sebanyak 80\% sedangkan pria hanya $20 \%$. Sebagian besar dari mereka berlatar belakang pendidikan sarjana yaitu sebanyak $78 \%$, diploma sebanyak 20\%, dan tamatan SMA 2\%. Artinya mayoritas karyawan yang diteliti memiliki latar belakang pendidikan yang cukup tinggi.

Kuesioner didistribusikan kepada para karyawan yang terpilih sebagai sampel untuk kajian ini. Data dikumpulkan dari karyawan yang bersedia berpartisipasi. Kegiatan pengumpulan data ini dilakukan pada saat jam istirahat kerja kantor. Kemudian, untuk keperluan pengolahan data dipergunakan program SPSS untuk analisis statistik (Pidekso, dkk., 2009).

Sebagaimana telah dipergunakan pada penelitian-penelitian sebelumnya, perilaku kreatif diukur melalui penilaian atasan terhadap kinerja kreatif bawahannya (misalnya, Brown, 1989; Madjar, Oldham, \& Pratt, 2002; Oldham \& Cummings, 1996; Scott \& Bruce, 1994). George and Zhou (2002) menyebutkan bahwa Cronbach's alpha untuk instrumen ini mencapai 0.98. Pengukuran kualitas komunikasi juga telah dipergunakan pada penelitian-penelitian sebelumnya. Kualitas komunikasi diukur melalui seberapa baik atau buruk komunikasi antara atasan dan bawahan (misalnya, Mulyana, 2001). Sedangkan dukungan training center diukur melalui proses peningkatan keterampilan kerja baik teknis maupun manajerial (Bangun, 2012).

Confirmatory Factor Analysis (CFA) melalui persamaan struktural (SEM) digunakan untuk menguji instrumen dan model struktural (Hair, et al., 2006). Sedangkan analisis regresi (Nazir, 2005) digunakan untuk menguji hipotesis peran kualitas komunikasi dan dukungan training center terhadap perilaku kreatif para pekerja call center.

\section{HASIL DAN PEMBAHASAN}

Tabel 1 menjelaskan hasil penilaian atasan mengenai variabel kinerja kreatif karyawan call center, yaitu 26,18\% responden dinilai sangat tinggi, 57,72\% responden dinilai tinggi, 15,01\% responden dinilai sedang dan 1,09\% responden dinilai rendah. Perilaku kreatif para pekerja call center 
didominasi penilaian yang tinggi dengan persentase 57,72\%. Nilai rata-rata mengenai kinerja kreatif sebesar 3,97 yang artinya tinggi karena berada pada kategori 3,40 - 4,19. Namun masih ada yang perlu mendapat perhatian mengenai penilaian pemimpin untuk selalu menyarankan cara baru dalam meningkatkan kinerja. Para pekerja telah memperlihatkan cara kerja dengan menyusun rencana dan jadwal yang memadai untuk implementasi gagasan baru; para pekerja call center sering mempunyai gagasan/ide baru dan inovatif; mereka selalu mengemukakan gagasan praktis dan baru untuk meningkatkan kinerja namun mereka adalah orang yang kurang berani menanggung risiko karena memiliki nilai di bawah rata-rata.

Tabel 1 Penilaian Atasan terhadap Perilaku Kreatif Para Pekerja Call Center

\begin{tabular}{|c|c|c|c|c|c|c|c|c|c|}
\hline No. & Pertanyaan & ST & $\mathbf{T}$ & S & $\mathbf{R}$ & SR & Total & Rata-rata & Ket \\
\hline 1. & $\begin{array}{l}\text { Ia sering menyarankan cara } \\
\text { baru untuk mencapai tujuan } \\
\text { atau sasaran }\end{array}$ & 24 & 60 & 13 & 3 & 0 & 405 & 4.05 & Tinggi \\
\hline 2. & $\begin{array}{l}\text { Ia selalu berusaha menemukan } \\
\text { teknologi, proses, teknik, } \\
\text { dan/atau pemikiran baru }\end{array}$ & 20 & 62 & 16 & 2 & 0 & 400 & 4.00 & Tinggi \\
\hline 3. & $\begin{array}{l}\text { Ia selalu menyarankan cara } \\
\text { baru untuk meningkatkan mutu }\end{array}$ & 20 & 67 & 10 & 3 & 0 & 404 & 4.04 & Tinggi \\
\hline 4. & $\begin{array}{l}\text { Ia selalu menjadi sumber } \\
\text { munculnya ide kreatif }\end{array}$ & 20 & 63 & 17 & 0 & 0 & 403 & 4.03 & Tinggi \\
\hline 5. & $\begin{array}{l}\text { Ia selalu menunjukkan } \\
\text { kreativitas dalam bekerja bila } \\
\text { diberi kesempatan }\end{array}$ & 27 & 51 & 20 & 2 & 0 & 403 & 4.03 & Tinggi \\
\hline 6 & $\begin{array}{l}\text { Ia selalu menyarankan cara } \\
\text { baru untuk meningkatkan } \\
\text { kinerja dalam melakukan } \\
\text { tugas-tugas pekerjaan. }\end{array}$ & 12 & 57 & 28 & 3 & 0 & 378 & 3.78 & Tinggi \\
\hline 7 & $\begin{array}{l}\text { Ia selau membuat rencana dan } \\
\text { jadwal yang memadai untuk } \\
\text { implementasi gagasan baru }\end{array}$ & 14 & 52 & 31 & 3 & 0 & 377 & 3.77 & Tinggi \\
\hline 8 & $\begin{array}{l}\text { Ia sering mempunyai } \\
\text { gagasan/ide baru dan inovatif }\end{array}$ & 19 & 57 & 22 & 2 & 0 & 393 & 3.93 & Tinggi \\
\hline 9 & $\begin{array}{l}\text { Ia selalu mengemukakan } \\
\text { gagasan praktis dan baru untuk } \\
\text { meningkatkan kinerja }\end{array}$ & 19 & 56 & 22 & 3 & 0 & 391 & 3.91 & Tinggi \\
\hline 10 & $\begin{array}{l}\text { Ia selalu memperkenalkan dan } \\
\text { mempertahankan gagasan itu di } \\
\text { hadapan orang lain }\end{array}$ & 30 & 54 & 14 & 2 & 0 & 412 & 4.12 & Tinggi \\
\hline 11 & $\begin{array}{l}\text { Ia selalu memiliki solusi kreatif } \\
\text { untuk memecahkan } \\
\text { permasalahan }\end{array}$ & 25 & 61 & 14 & 0 & 0 & 411 & 4.11 & Tinggi \\
\hline 12 & $\begin{array}{l}\text { Ia sering mempunyai suatu } \\
\text { cara pendekatan baru untuk } \\
\text { menyelesaikan permasalahan }\end{array}$ & 26 & 52 & 20 & 2 & 0 & 402 & 4.02 & Tinggi \\
\hline 13 & $\begin{array}{l}\text { Ia adalah orang yang berani } \\
\text { menanggung risiko }\end{array}$ & 14 & 52 & 31 & 3 & 0 & 377 & 3.77 & Tinggi \\
\hline & Persentase & 26.18 & 57.72 & 15.01 & 1.09 & 0 & 100 & 3,97 & Tinggi \\
\hline
\end{tabular}


Berdasarkan kuesioner yang telah disebarkan kepada responden, maka dapat diketahui mengenai tanggapan responden mengenai kualitas komunikasi dan dukungan training center. Tabel 2 memperlihatkan hasil jawaban untuk seluruh pernyataan mengenai variabel pelatihan yaitu 23,05\% responden menyatakan sangat setuju, 62,38\% responden menyatakan setuju, 13,76\% responden menyatakan ragu-ragu, dan 0,81\% responden menyatakan tidak setuju. Dengan demikian jawaban dari responden call center didominasi jawaban setuju dengan persentase $62,38 \%$. Nilai rata-rata mengenai variabel pelatihan sebesar 3,97 yang artinya baik karena berada pada kategori 3,40 - 4,19.

Tabel 2 Analisis Pernyataan Responden Mengenai Pelatihan

\begin{tabular}{lcccccccc}
\hline No & \multicolumn{1}{c}{ PS } & Pertanyaan & KS & TS & STS & Total & Rata-rata & Ket \\
\hline $\begin{array}{l}\text { Pelatihan yang diberikan } \\
\text { perusahaan dapat } \\
\text { meningkatkan kualitas kerja } \\
\text { karyawan }\end{array}$ & 22 & 63 & 14 & 1 & 0 & 406 & 4.06 & Baik \\
\hline $\begin{array}{l}\text { Materi yang diberikan dalam } \\
\text { pelatihan dapat } \\
\text { meningkatkan kemampuan } \\
\text { kerja karyawan }\end{array}$ & 19 & 66 & 13 & 2 & 0 & 402 & 4.02 & Baik \\
\hline $\begin{array}{l}\text { Materi yang diberikan dalam } \\
\text { pelatihan sesuai dengan } \\
\text { kebutuhan kerja }\end{array}$ & 18 & 69 & 11 & 2 & 0 & 403 & 4.03 & Baik \\
\hline $\begin{array}{l}\text { Metode yang digunakan } \\
\text { dalam pelatihan } \\
\text { memudahkan karyawan } \\
\text { untuk memahami materi } \\
\text { pelatihan }\end{array}$ & 17 & 66 & 16 & 1 & 0 & 399 & 3.99 & Baik \\
\hline $\begin{array}{l}\text { Instruktur dapat } \\
\text { menyampaikan materi } \\
\text { dengan baik sehingga mudah } \\
\text { dipahami oleh peserta } \\
\text { pelatihan }\end{array}$ & 23 & 56 & 20 & 1 & 0 & 401 & 4.01 & Baik \\
\hline $\begin{array}{l}\text { Instruktur dapat memotivasi } \\
\text { peserta agar lebih memahami } \\
\text { materi pelatihan }\end{array}$ & 21 & 63 & 15 & 1 & 0 & 404 & 4.04 & Baik \\
\hline $\begin{array}{l}\text { Kelengkapan peralatan } \\
\text { pelatihan yang disediakan } \\
\text { perusahaan sudah memadai }\end{array}$ & 10 & 62 & 27 & 1 & 0 & 381 & 3.81 & Baik \\
\hline $\begin{array}{l}\text { Fasilitas yang disediakan } \\
\text { perusahaan menciptakan } \\
\text { suasana yang menunjang } \\
\text { pelaksanaan pelatihan }\end{array}$ & 21 & 61 & 16 & 2 & 0 & 401 & 4.01 & Baik \\
\hline $\begin{array}{l}\text { Setelah mendapatkan } \\
\text { pelatihan kreatifitas } \\
\text { karyawan meningkat }\end{array}$ & 20 & 57 & 21 & 2 & 0 & 395 & 3.95 & Baik \\
\hline $\begin{array}{l}\text { Pelaksanaan program } \\
\text { pelatihan sesuai dengan } \\
\text { waktu / jadwal yang telah } \\
\text { ditetapkan perusahan }\end{array}$ & 12 & 56 & 29 & 3 & 0 & 377 & 3.77 & Baik \\
\hline Persentase & 23.05 & 62.38 & 13.76 & 0.81 & 0 & 100 & 39,69 & Baik \\
\hline
\end{tabular}

Tabel 3 menunjukkan hasil jawaban responden untuk seluruh pernyataan mengenai variabel komunikasi yaitu 30,13\% responden menyatakan sangat setuju, 55,56\% responden menyatakan setuju, $13,62 \%$ responden menyatakan ragu-ragu dan $0,69 \%$ responden menyatakan tidak setuju. Dengan demikian jawaban dari responden call center didominasi jawaban setuju dengan persentase 55,56\%. 
Nilai rata-rata mengenai variabel komunikasi sebesar 4,03 yang artinya baik karena berada pada kategori 3,40-4,19.

Tabel 3 Analisis Pernyataan Responden Mengenai Komunikasi

\begin{tabular}{|c|c|c|c|c|c|c|c|c|c|}
\hline No. & Pertanyaan & SS & $\mathrm{S}$ & KS & TS & STS & Total & Rata-rata & Ket \\
\hline 1. & $\begin{array}{l}\text { Saya merasa bahwa pimpinan } \\
\text { memberikan perhatian kepada } \\
\text { bawahan. }\end{array}$ & 22 & 63 & 14 & 1 & 0 & 406 & 4.06 & Baik \\
\hline 2. & $\begin{array}{l}\text { Saya merasa bahwa pimpinan } \\
\text { terbuka dalam masalah } \\
\text { pekerjaan kepada bawahan. }\end{array}$ & 19 & 66 & 13 & 2 & 0 & 402 & 4.02 & Baik \\
\hline 3. & $\begin{array}{l}\text { Pimpinan selalu meminta } \\
\text { pendapat kepada bawahan } \\
\text { dalam pekerjaan }\end{array}$ & 18 & 69 & 11 & 2 & 0 & 403 & 4.03 & Baik \\
\hline 4. & $\begin{array}{l}\text { Dengan adanya petunjuk } \\
\text { tertulis, laporan papan } \\
\text { informasi dan media lainnya } \\
\text { dapat memudahkan saya dalam } \\
\text { bekerja }\end{array}$ & 17 & 66 & 16 & 1 & 0 & 399 & 3.99 & Baik \\
\hline 5. & $\begin{array}{l}\text { Saya rasa rekan kerja yang } \\
\text { lebih dahulu mengetahui } \\
\text { informasi terbaru selalu } \\
\text { memberitahu saya. }\end{array}$ & 23 & 56 & 20 & 1 & 0 & 401 & 4.01 & Baik \\
\hline 6. & $\begin{array}{l}\text { Seluruh karyawan dapat } \\
\text { berkonsultasi dengan pimpinan } \\
\text { mengenai informasi atau } \\
\text { kebijakan yang baru. }\end{array}$ & 25 & 55 & 17 & 3 & 0 & 402 & 4.02 & Baik \\
\hline 7. & $\begin{array}{l}\text { Saya dapat mengetahui } \\
\text { dengan cepat mengenai } \\
\text { informasi terbaru yang ada di } \\
\text { kantor. }\end{array}$ & 32 & 45 & 23 & 0 & 0 & 409 & 4.09 & Baik \\
\hline 8. & $\begin{array}{l}\text { Pimpinan saya memberikan } \\
\text { penjelasan yang lebih dari } \\
\text { yang saya harapkan mengenai } \\
\text { pekerjaan }\end{array}$ & 25 & 45 & 28 & 2 & 0 & 393 & 3.93 & Baik \\
\hline 9. & $\begin{array}{l}\text { Saya dapat memahami } \\
\text { penjelasan mengenai pekerjaan } \\
\text { yang diberikan oleh pimpinan. }\end{array}$ & 33 & 46 & 20 & 1 & 0 & 411 & 4.11 & Baik \\
\hline 10. & $\begin{array}{l}\text { Saya merasa informasi yang } \\
\text { disampaikan pimpinan tentang } \\
\text { pelaksanaan tugas yang } \\
\text { diberikan selalu jelas. }\end{array}$ & 29 & 49 & 21 & 1 & 0 & 406 & 4.06 & Baik \\
\hline & Persentase & 30.13 & 55.56 & 13.62 & 0.69 & 0 & 100 & 40,32 & Baik \\
\hline
\end{tabular}

Dalam penelitian ini didapatkan hasil pengujian pengaruh komunikasi dan dukungan training center terhadap perilaku kreatif para pekerja call center. Besarnya pengaruh/kontribusi pelatihan dan komunikasi terhadap kinerja kreatif karyawan call center adalah sebesar 70\%; sedangkan sisanya sebesar 30\% ditentukan oleh faktor lain di luar variabel yang tidak diteliti. Dari hasil perhitungan uji hipotesis 1 , diperoleh hasil bahwa $t_{\text {hitung }}=15,050$ lebih besar dari $t_{\text {tabel }}=1,639$; hal ini menunjukkan pelatihan berpengaruh positif terhadap kinerja kreatif karyawan. Demikian juga untuk perhitungan uji hipotesis 2, dapat dilihat bahwa $t_{\text {hitung }}=8,840$ lebih besar dari $t_{\text {tabel }}=1,639$; hal ini menunjukkan komunikasi berpengaruh positif terhadap kinerja kreatif karyawan. Selanjutnya, dari perhitungan uji hipotesis 3, dapat dilihat bahwa $t_{\text {hitung }}=15,050$ lebih besar dari $t_{\text {tabel }}=1,639$; hal ini menunjukkan bahwa pelatihan dan komunikasi berpengaruh positif terhadap kinerja kreatif karyawan. 


\section{Diskusi}

Pelatihan kerja diselenggarakan dan diarahkan untuk membekali, meningkatkan, dan mengembangkan kompetensi kerja guna meningkatkan kemampuan, produktivitas, dan kesejahteraan. Berdasarkan hasil penelitian bahwa tanggapan responden atas indikator-indikator pelatihan untuk para pekerja call center saat ini dapat dikatakan "Baik". Hal ini didukung oleh dimensi-dimensi pelatihan, seperti: menentukan materi, menentukan metode pelatihan, dan memilih pelatih yang dibutuhkan; namun masih ada yang perlu mendapat perhatian, seperti: mempersiapkan fasilitas yang dibutuhkan, memilih para peserta, dan melaksanakan program karena masih memiliki nilai di bawah rata-rata.

Besarnya pengaruh pelatihan terhadap kinerja kreatif karyawan call center didukung oleh hasil penelitian sebelumnya seperti yang dilakukan oleh Noraga (2010) bahwa terdapat pengaruh yang kuat antara pelatihan karyawan terhadap prestasi kerja karyawan. Hal yang membedakan dengan penelitian sebelumnya adalah variabel dependen (Y) dan objek yang diteliti. Di sisi lain, komunikasi sebagai proses pertukaran informasi antarindividu melalui suatu sistem yang biasa (lazim) baik dengan simbolsimbol, sinyal-sinyal maupun perilaku atau tindakan juga penting untuk dibahas. Berdasarkan hasil penelitian ini, tanggapan responden atas indikator-indikator komunikasi yang dinilai oleh para pekerja call center saat ini dapat dikatakan "Baik". Hal ini didukung oleh situasi-situasi yang terkait dengan kualitas komunikasi, seperti: iklim organisasi, kemudahan informasi, penyebaran informasi, dan ketepatan pesan; namun masih ada yang perlu mendapat perhatian, seperti: adanya petunjuk dan laporan papan informasi, serta penjelasan pimpinan karena memiliki nilai yang masih di bawah ratarata.

Besarnya pengaruh komunikasi terhadap kinerja karyawan call center ini juga sesuai dengan penelitian sebelumnya seperti yang dilakukan oleh O’Neill (2008) meskipun ada perbedaan sedikit pada variabel dependen dan objek yang diteliti. Hasil menunjukkan bahwa komunikasi internal yang dilakukan pada Kantor Balai Besar Wilayah Sungai Citanduy mempunyai hubungan yang kuat terhadap tingkat konflik karyawan.

Yang dibutuhkan oleh bisnis adalah penerapan proses kreatif pada masalah, isu, kesempatan, dan peluang yang ada pada saat ini. Sementara produk kreatif adalah kemampuan untuk melahirkan sesuatu benda atau hal yang sebelumnya sama sekali belum ada untuk dipergunakan. Ide yang kreatif dikaitkan dengan ide yang baru, yakni paling tidak untuk orang yang bersangkutan ide kreatif ini dapat melibatkan sebuah usaha penggabungan dua hal atau lebih ide-ide secara langsung (Adair, 2011).

Kreativitas adalah hal yang sangat populer belakangan ini. Setiap orang menyadari bahwa untuk dapat bertahan dan memenangkan persaingan perusahaan-perusahaan dan setiap karyawannya harus kreatif apapun jenis profesi dan jobdesc yang dikerjakannya. Menurut para ahli, seseorang yang kreatif selalu melihat segala sesuatu dengan cara berbeda dan baru, dan biasanya tidak dilihat oleh orang lain. Orang yang kreatif, pada umumnya, mengetahui permasalahan dengan sangat baik dan disiplin, biasanya dapat melakukan sesuatu yang menyimpang dari cara-cara tradisional. Proses kreativitas melibatkan adanya ide-ide baru, berguna, dan tidak terduga namun dapat diimplementasikan.

Pada dasarnya kreativitas dapat terjadi pada semua pekerja apapun profesi yang dilakoninya di tempat mereka bekerja. Dengan menumbuhkan kreativitas dalam bekerja akan dapat meminimalkan terjadinya stres dalam bekerja yang sebenarnya akan berdampak pada produktivitas diri dan kerugian pada perusahaan juga. Tentang aktor yang memengaruhi karyawan untuk keatif di tempat kerja, beberapa penelitian memperlihatkan bahwa dorongan kreativitas datang dari pihak lain (Setiadi, Ali, \& Aafaqi, 2010). Yang dimaksud pihak lain bisa atasan atau manajer, rekan kerja, ataupun teman di luar lingkungan kerja. Misalnya, untuk menciptakan kreativitas dibutuhkan lingkungan kerja kondusif yang 
menyenangkan (fun), penuh rasa humor, spontan, dan memberi ruang bagi individu untuk melakukan berbagai permainan atau percobaan (Setiadi, Boediprasetya, \& Wahdiaman, 2012).

\section{SIMPULAN}

Tuntutan berperilaku kreatif bagi pelaku bisnis di industri call center memerlukan peran komunikasi yang terbangun secara kondusif di tempat kerja. Berdasarkan hasil penelitian ini, tanggapan responden terhadap indikator-indikator komunikasi yang dinilai oleh para pekerja call center saat ini dapat dikatakan "Baik". Hal ini didukung oleh situasi-situasi yang terkait dengan kualitas komunikasi seperti: iklim organisasi, kemudahan informasi, penyebaran informasi, dan ketepatan pesan. Para pekerja telah memperlihatkan cara kerja dengan menyusun rencana dan jadwal yang memadai untuk implementasi gagasan baru. Para pekerja call center juga memperlihatkan penciptaan gagasan/ide baru dan inovatif. Mereka selalu mengemukakan gagasan praktis dan baru untuk meningkatkan kinerja namun mereka adalah orang yang kurang berani menanggung risiko. Untuk meningkatkan keberanian mereka dalam menyikapi risiko perlu dibekali kemampuan dan sering dilatih untuk menghadapi risiko dalam pekerjaan. Pelatihan kerja diselenggarakan dan diarahkan untuk membekali, meningkatkan, dan mengembangkan kompetensi kerja mereka guna meningkatkan kemampuan, produktivitas, dan kesejahteraan. Hal ini didukung oleh dimensi-dimensi pelatihan seperti: menentukan materi, menentukan metode pelatihan, dan memilih pelatih yang dibutuhkan. Meskipun demikian, masih ada beberapa hal yang perlu mendapat perhatian, seperti: mempersiapkan fasilitas yang dibutuhkan, memilih para peserta dan melaksanakan program kerja, karena masih memiliki kinerja di bawah rata-rata.

\section{DAFTAR PUSTAKA}

Adair, J. (2011). John Adair's 100 Greatest Ideas for Amazing Creativity. North Mankato: Capstone.

Bangun, W. (2012). Manajemen Sumber Daya Manusia. Bandung: Erlangga

Brown, R.T. (1989). Creativity: What are we to measure? In Glover, J.A., Ronning, R.R., \& Reynold, C.R., (Eds). Handbook of creativity. Cambridge: Cambridge University Press.

Dessler, G. (2006). Manajemen Sumberdaya Manusia (terjemahan). Jakarta: INDEKS.

Effendy, O. U. (2003). Ilmu Komunika. Cetakan ke-17. Bandung: Remaja Rosdakarya.

Foster, J. (2012). Creativity: The Hub of Real Achievement. Thousand Oaks, CA: SAGE.

George, J. M. and Zhou, J. (2002). Understanding when bad moods foster creativity and good ones don't: The role of context and clarity of feelings. Journal of Applied Psychology, 87, 687-697.

Hair, J. F., Black, W. C., Babin, B. J., Anderson, R. E., \& Tatham, R. L. (2006). Multivariate Data Analysis. $6^{\text {th }}$ ed. New Jersey: Pearson Education.

Jerry, A., and Sunaryo, I. (2009). Employee Contribution and Satisfaction in Call Centre Performance. Proceeding paper of the International conference of APIEMS, Kitakyushu, Dec. 14-16, 2009. 
Madjar, N., Oldham, G.R., \& Pratt, M., (2002). There's no place like home? The contributions of work and nonwork creativity support to employees creative performance. Academy of Management Journal, 45(4), 757-767.

Mangkunegara, A. P. (2004). Manajemen Sumber Daya Perusahaan. Cetakan Kelima. Bandung: Remaja Rosdakarya.

Mathis, R. L. dan Jackson, J. H. (2004). Human Resource Management. Buku 2. Edisi pertama. Jakarta: Salemba Empat.

Mulyana. (2001). Komunikasi Organisasi. Cetakan kedua, Bandung: Remaja Rosdakarya.

Nazir, M. (2005). Metode Penelitian. Cetakan Kelima. Jakarta: Penerbit Ghalia Indonesia.

Noe, R. A. (2012). Employee Training \& Development. Boston: McGraw-Hill, Irwin

Noe, R. A., Hollenbeck, J. R., Gerhart, B., and Wright, P. M. (2006). Human Resources Management, Gaining a Competitive Advantage. $5^{\text {th }}$ Ed. Boston: McGraw-Hill, Irwin.

Noraga, T. F. (2010). Pengaruh Motivasi dan Pelatihan Terhadap Prestasi Kerja Karyawan pada PT. Pertamina (Persero) UPms IV Semarang (tesis tidak dipublikasikan). Semarang: Universitas Dipoonegoro.

O’Neill. (2008). Measuring the Impact of Employee Communication on Employee Comprehension and Action: A Case Study of a Major International Firm. Public Relations Journal, 2(2), 1-17.

Oldham, G. R., and Cummings, A. (1996). Employee creativity: personal and contextual factors at work. Academy of Management Journal, 39, 607-634.

Pidekso, A., Sulistiyani, S., Sumartini, dan Alek (2009). SPSS 16.0 Untuk Pengolahan Statistik. Semarang: Andi.

Purwanto, D. (2006). Komunikasi Bisnis. Jakarta: Erlangga

Scott, S. G., and Bruce, R. A. (1994). Determinants of innovative behavior: a path model of individual innovation in the workplace. Academy of Management Journal, 37, 580-607.

Setiadi, N.J., Ali, A.J. and Aafaqi, R. (2010). The multiplicative effects of personality dimensions on creative behavior among Indonesian radio station managers. Journal Accounting Business and Management, 17(2), 107-121.

Setiadi, N.J., Boediprasetya, A., \& Wahdiaman (2012). Boosting Indonesia's creative industries: Identification of people's characteristics and creative behaviour. Quaestiones Geographicae, 31(4), 53-62.

Sprigg, C. A., Smith, P. R., \& Jackson, P. R. (2003). Psychosocial risk factors in call centers: An evaluation of Work design and well-being. The University of Sheffield, Health and Safety Laboratory and UMIST for the Health and Safety Executive (Research Report). Diakses 20 Mei 2013 dari http://www.hse.gov.uk/research/rrpdf/rr169.pdf. 


\section{LAMPIRAN}

\section{Ungkapan Terima Kasih}

Penelitian ini didukung oleh Hibah Penelitian Kompetensi dari Dit. Litabmas Dikti, Kemdikbud, melalui grants nomor: 043/SP2H/PL/DIT.LITABMAS/V/2013. Terima kasih kepada anggota tim peneliti Dr. Nina Nurani, Agoestiana Boediprasetya, dan Lia Amaliawiaty, serta keterlibatan para mahasiswa antara lain: Riski Dani, Galih, dan Lusi 